\title{
RANCANG BANGUN WIRELESS ELEKTROKARDIOGRAM (EKG)
}

\author{
RARA AMITA PUTRI*, JAJAT YUDA MINDARA, SRI SURYANINGSIH \\ Departemen Fisika Fakultas MIPA Universitas Padjadjaran, \\ Jl. Raya Bandung-Sumedang Km 21, Jatinangor 45363 \\ *email : rara12003@mail.unpad.ac.id
}

\begin{abstract}
Abstrak. Jantung adalah bagian dari tubuh manusia yang memiliki aktivitas listrik atau dikenal dengan bioelektrik. Aktivitas kelistrikan jantung dapat direkam. Aktivitas jantung akan menghasilkan suatu gelombang EKG yang terdiri dari gelombang P, kompleks gelombang QRS, dan gelombang T. Perekaman aktivitas jantung dapat dimanfaatkan untuk menganalisa bagaimana karakteristik dari jantung. Perekaman aktivitas jantung ini dikenal dengan istilah elektrokardiogram (EKG). EKG yang banyak digunakan saat ini berupa EKG dengan pengiriman data menggunakan kabel. Penggunaan kabel membatasi jarak pengaksesan hasil rekaman EKG. Untuk jarak yang lebih jauh, EKG yang menggunakan kabel harus menambah panjang kabel yang berarti menambah biaya produksi EKG. Penelitian ini bertujuan untuk merancang dan membangun suatu sistem perangkat keras dan perangkat lunak untuk perekaman detak jantung dengan sistem wireless. Pembuatan sistem dilakukan dengan menggunakan elektroda tembaga sebagai penyadap detak jantung. Hasil sadapan tersebut dimasukkan pada rangkaian pengondisi sinyal dan diolah agar bisa dikirimkan melalui wireless dengan sistem modulasi - demodulasi. Hasil perekaman ditampilkan dalam komputer menggunakan perangkat lunak dan dilakukan sesuai dengan gelombang EKG yang diinginkan dalam radius $1 \mathrm{~m}^{2}$.
\end{abstract}

Kata kunci : Bioelektrik, Elektrokardiogram, Gelombang EKG, Wireless

Abstract. The heart is a part of the human body that has electrical activity, or known as bioelectricity. The heart's electrical activity can be recorded. Cardiac activity will generate an ECG wave comprising the P wave, QRS complex wave and T wave. Recording cardiac activity can be used to analyze the characteristic of heart. Recording the activity of the heart is known as the electrocardiogram (ECG). Recently, an ECG is used with data transmission cables in general. Using cables will limit the distance of accessing the results of the ECG recording. For longer distances, the ECG using a cable must add the cable length that means increasing production costs of ECG. This research aims to design and build a system of hardware and software for recording the heartbeat with a wireless system. Making the system was done using a copper electrode as a tapper heartbeat. The results leads included in the circuit and signal conditioning was processed to be sent through a wireless system with modulation - demodulation. The results were displayed on a computer using software and had been done in accordance with the desired ECG waveform in radius $1 \mathrm{~m}^{2}$.

Keywords : Bioelectric, Electrocardiogram, ECG wave, Wireless

\section{Pendahuluan}

Tubuh manusia terdiri dari bagian plasma yang memiliki potensi mengeluarkan listrik yang sering dikenal dengan istilah bioelektrik [1]. Bagian plasma tubuh yang mengandung bahan elektrolit serta aktivitas tubuh lain yang memicu 
perbedaan muatan listrik inilah yang mengakibatkan tubuh manusia mampu menghasilkan sinyal listrik yang akan mengatur operasi syaraf, otot, dan organ tubuh lainnya sehingga dapat dikatakan bahwa pada dasarnya seluruh fungsi organ dalam tubuh ada hubungannya dengan bioelektrik [2]. Perekaman listrik pada tubuh manusia dapat dilakukan pada berbagai organ tubuh. Salah satunya adalah perekaman aktivitas organ jantung. Perekaman aktivitas jantung dikenal dengan istilah elektrokardiogram (EKG). Elektrokardiogram (EKG) adalah suatu gambaran dari potensial listrik yang dihasilkan oleh aktivitas listrik otot jantung. EKG merupakan rekaman informasi kondisi jantung yang diambil dengan elektrokardiograf yang ditampilkan melalui monitor atau dicetak pada kertas dalam bentuk gelombang EKG atau gelombang PQRST [3]. Dengan kata lain, hasil perekaman ini dapat menunjukkan karakteristik dari jantung. Gambar 1 menunjukkan gelombang EKG pada manusia normal.

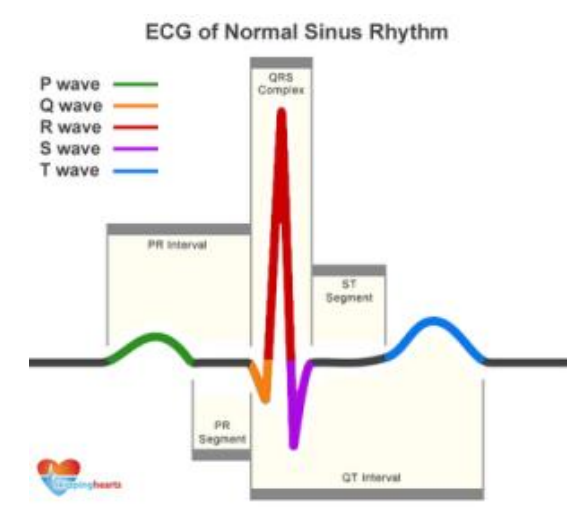

Gambar 1. Gelombang EKG Normal[4]

EKG yang sering digunakan saat ini adalah EKG yang masih menggunakan kabel sebagai pengirim data dan ditampilkan pada layar EKG atau dicetak pada kertas. Penggunaan kabel membuat EKG kurang fleksibel karena membatasi pengaksesan hasil rekaman EKG hanya dalam jarak dekat dengan pasien [5]. Pengembangan EKG menggunakan wireless akan menambah fleksibilitas sehingga pemantauan terhadap jantung tidak lagi terbatas jarak oleh panjang kabel [6,7]. Selain itu penambahan panjang kabel secara ekonomis akan mengeluarkan biaya yang lebih besar sehingga biaya produksi alat bertambah.

Penelitian ini bertujuan untuk merancang dan membangun sistem perangkat keras (hardware) dan perangkat lunak (software) untuk perekaman detak jantung dengan sistem wireless. Wireless yang digunakan memanfaatkan prinsip modulasi demodulasi frekuensi. Proses modulasi frekuensi sendiri adalah teknik mengubah karakter frekuensi suatu sinyal informasi sesuai dengan karakter gelombang pembawanya. Hasil modulasi frekuensi ditunjukkan dengan persamaan 1 [6] :

$$
\Psi(t)=\Psi_{c} \cos \left[\omega_{c} t+\varphi(t)\right]
$$

Proses penyadapan yang dilakukan pada penelitian berupa penyadapan bipolar yaitu dengan meletakkan tiga buah elektroda pada tubuh bagian tangan kanan, tangan kiri, dan kaki sebagai ground [1] (Gambar 2). Elektroda ini kemudian dihubungkan dengan suatu rangkaian pengondisi sinyal EKG seperti pada Gambar 3. 


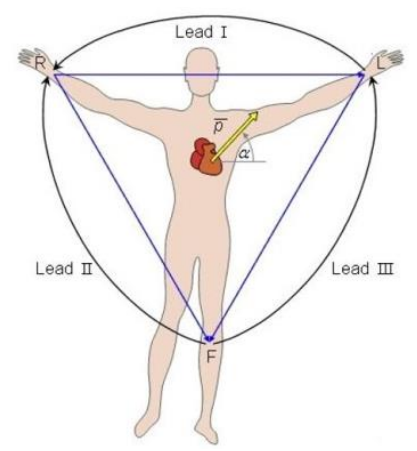

Gambar 2. Sadapan Bipolar

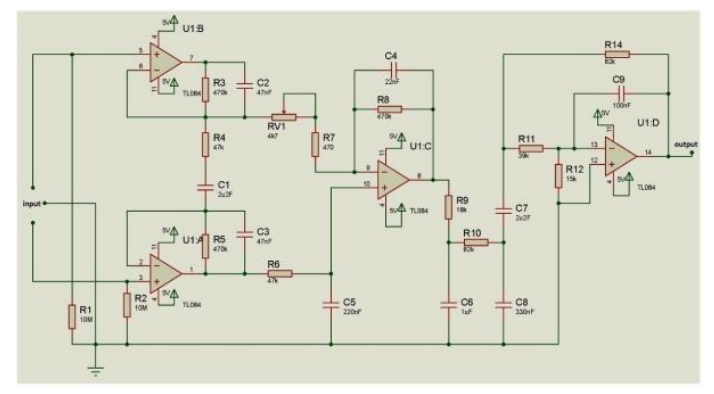

Gambar 3. Rangkaian Pengondisi Sinyal EKG[7]

\section{Metode Penelitian}

Tahap awal yaitu tahap kajian literatur mengenai objek yang akan diteliti yaitu detak jantung manusia. Selain itu studi juga dilakukan pada utilitas elektronik yang akan digunakan dalam perancangan dan pembuatan alat yaitu rangkaian penguat instrumentasi, rangkaian komparator, rangakaian konverter tegangan ke frekuensi, rangkaian wireless dengan sistem modulasi - demodulasi, rangkaian konverter frekuensi ke tegangan, rangkaian ADC, serta perangkat lunak yang digunakan. Selanjutnya adalah perancangan alat berupa perancangan perangkat keras dan perangkat lunak. Tahap yang ketiga adalah tahap pembuatan alat yaitu pembuatan perangkat keras dan perangkat lunak. Tahap yang keempat adalah tahap pengujian. Pada tahap pengujian, alat yang telah dirancang bangun diuji apakah sudah sesuai dengan tujuan penelitian. Alur penelitian ini diilustrasikan oleh Gambar 4.

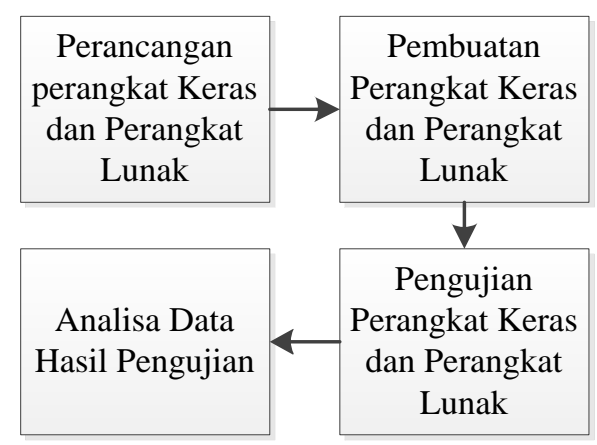

Gambar 4. Diagram alir penelitian 
Perancangan seluruh perangkat keras alat ditunjukkan pada Gambar 5. Perangkat keras yang dirancang dan dibuat dalam penelitian berupa rangkaian pengondisi sinyal EKG yang diatur agar mampu menguatkan amplitudo detak jantung yang memiliki nilai pada rentang $0.1 \mathrm{mV}$ sampai $1 \mathrm{mV}$. Rangkaian selanjutnya adalah konverter tegangan ke frekuensi agar sinyal yang masih berupa tegangan dapat dimodulasi dan dikirim melalui wireless. Sinyal berupa gelombang EKG yang telah dikirim melalui wireless selanjutnya diterima oleh receiver dan diubah menjadi besaran tegangan oleh rangkaian konverter frekuensi ke tegangan.

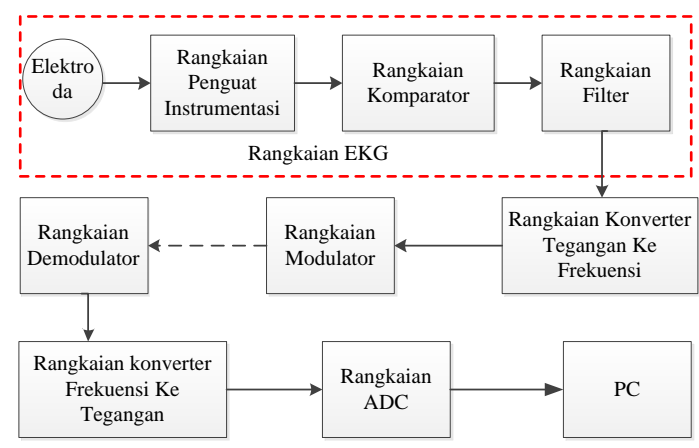

Gambar 5. Diagram Rancangan Perangkat Keras

Data analog hasil pengukuran diubah menjadi data digital menggunakan ADC berbasis IC MAX 195. Penggunaan IC MAX 195 untuk ADC disebabkan oleh kemampuannya untuk mengkonversi data dalam waktu $10 \mu$ s dan lebar data yang besar yaitu 16-bit [8]. Data yang telah diubah menjadi data digital selanjutnya ditampilkan dalam software berbasis Bahasa Pascal.

Pengujian alat dilakukan dengan subjek berusia antara 20 - 60 tahun yang diukur detak jantungnya. Subjek diukur detak jantungnya dalam keadaan relaksasi.

\section{Hasil dan Pembahasan}

Hasil penelitian berupa Grafik EKG atau Grafik PQRST dari tiga orang subjek yaitu pria berusia 56 tahun, wanita berusia 21 tahun, dan pria berusia 22 tahun. Pengujian dilakukan dalam radius $1 \mathrm{~m}^{2}$ antara transmitter dan receiver yang digunakan. Subjek yang diukur detak jantungnya dikondisikan dalam keadaan relaksasi. Berikut ini adalah gambar hasil pengujian yang telah dilakukan.

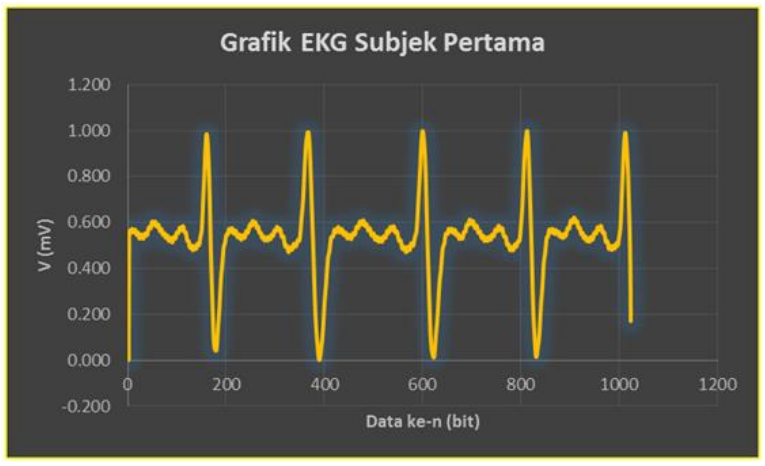

Gambar 6. Grafik EKG yang Dihasilkan Dari Subjek Pertama 


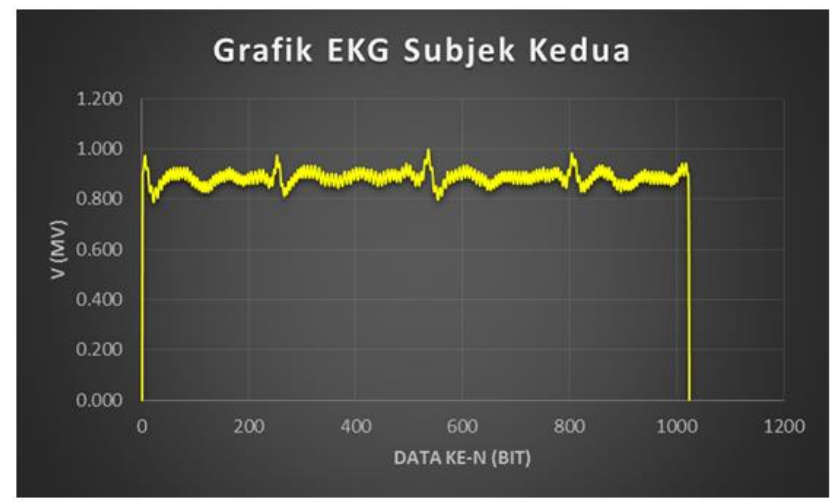

Gambar 7. Grafik EKG yang Dihasilkan Dari Subjek Kedua

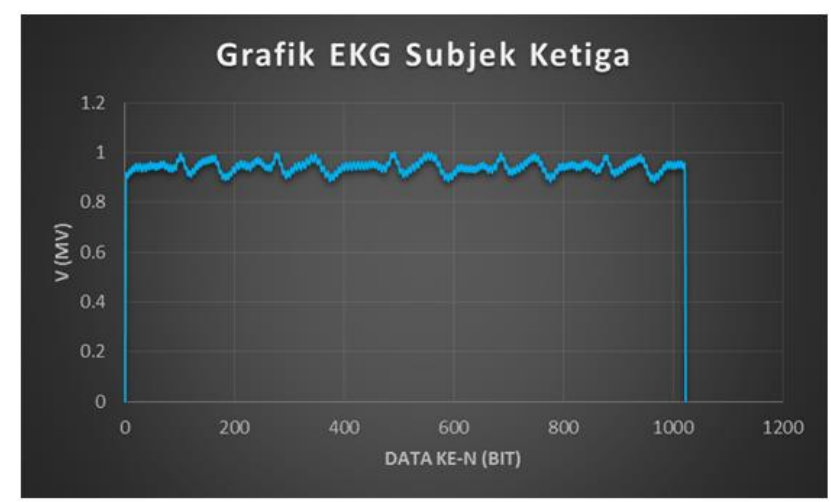

Gambar 8. Grafik EKG yang dihasilkan Dari Subjek Ketiga

Berdasarkan data pengujian oleh dokter ahli, rata - rata jumlah detak jantung yang dimiliki orang dewasa dalam kondisi relaksasi yaitu 72 - 80 kali permenit [9]. Jumlah detak tersebut jika diubah ke dalam periode yaitu 0,67 - $1 \mathrm{~s}$ atau rata rata $0,86 \mathrm{~s}$ [10]. Hasil pengujian pada penelitian ini menghasilkan Gelombang PQRST dari subjek pertama (lihat Gambar 6) yang memiliki periode detak jantung 0,66 s, Gelombang PQRST subjek kedua (Gambar 7) yang memiliki periode $0,80 \mathrm{~s}$, dan Gelombang PQRST subjek ketiga (Gambar 8) dengan periode 0,67 s. Dari pengujian ini diperoleh pula bahwa frekuensi yang diterima dari subjek pertama yaitu $1,52 \mathrm{~Hz}$, dari subjek kedua $1,24 \mathrm{~Hz}$, dan dari subjek ketiga yaitu 1,49 Hz. Nilai periode tersebut diperoleh dengan merata - rata periode setiap puncak ke puncak yang dihasilkan. Nilai ini menunjukkan proses pengiriman gelombang EKG hingga proses perekaman yang dilakukan sudah terjadi. Periode yang terukur erat hubungannya dengan proses pengiriman frekuensi yang dilakukan pada rangkaian terintegrasi ini.

Pada proses perekaman di rumah sakit (dilakukan oleh ahli) subjek yang akan diperiksa detak jantungnya harus mengikuti beberapa prosedur. Prosedur yang harus diikuti diantaranya subjek yang akan diukur detak jantungnya lebih baik dalam keadaan berbaring atau dalam kondisi istirahat total dan bertelanjang dada. Hal ini dimaksudkan agar tidak terjadi gerakan yang dapat mengakibatkan gangguan selama proses perekaman. Elektroda yang digunakan cukup sensitif terhadap gerakan sehingga sedikit gerakan yang terjadi pada otot akan 
mengakibatkan grafik yang tidak memuaskan. Logam yang ada pada tubuh atau yang menempel pada baju lebih baik dihindari. Selain itu kontak antara elektroda dengan kulit harus baik. Kontak yang baik bisa terjadi diantaranya dengan penggunaan jelly khusus dan penggunaan alkohol untuk membersihkan bagian kulit yang akan dipasangi elektroda. Beberapa prosedur ini tidak dilakukan selama proses perekaman detak jantung dalam penelitian ini.

Grafik EKG yang dihasilkan dari penelitian ini masih memiliki noise. Penggunaan utilitas pada wireless EKG yang cukup banyak adalah salah satu penyebab mengapa terjadi noise pada alat ini. Frekuensi dan tegangan yang dihasilkan dari aktivitas jantung memiliki nilai yang relatif kecil. Frekuensi berkisar pada nilai 1 $\mathrm{Hz}$ dan tegangan sebesar $1 \mathrm{mV}$. Oleh sebab itu proses perekaman detak jantung yang seharusnya hanya mengukur kondisi detak jantung dapat mudah mengalami gangguan atau hambatan karena rentang nilai frekuensi dan tegangan yang kecil sedangkan utilitas yang dipasang cukup banyak. Noise ini menunjukkan adanya kestabilan yang kurang dari alat.

\section{Kesimpulan}

Simpulan yang diperoleh dari penelitian ini yaitu telah berhasil dibuat suatu rancangan elektrokardiogram (EKG) dengan sistem wireless. Alat ini terdiri dari beberapa utilitas yaitu elektroda tembaga, rangkaian pengondisi sinyal yang memiliki tingkat korelasi $\mathrm{R}^{2}=0,9967$, rangkaian konverter tegangan ke frekuensi dengan tingkat korelasi $\mathrm{R}^{2}=0,9935$, wireless dengan sistem modulasi demodulasi dengan $\mathrm{R}^{2}=0,9992$, rangkain konverter frekuensi ke tegangan dengan tingkat korelasi $\mathrm{R}^{2}=1$ dan rangakain ADC dimana tingkat korelasinya adalah $\mathrm{R}^{2}=0,9994$. Wireless $\mathrm{EKG}$ ini telah mampu merekam aktivitas jantung dalam radius $1 \mathrm{~m}^{2}$ sehingga dapat diketahui karakteristik dari jantung dengan melihat gelombang EKG yang dihasilkan dalam bentuk gelombang PQRST.

\section{Daftar Pustaka}

1. Gabriel, J.F. 1996. Fisika Kedokteran. Jakarta : ECG.

2. Cameron, J.R. and J.G. Skrofonick. 1978. Medical Physics. John Wiley and Sons.

3. J. S. Walker. 1999. Wavelet and Their Scientific Applications. CRC Press.

4. Abdullah, Rozi dr. 2012. EKG Dasar. www.bukusakudokter.org. (diakses pada 14 September 2015).

5. Liu, Y.D., Liu Y.C., Liang S. F., Lan K. C. Young C. P., Chang D. W., Su a. W. Y., Shaw F. Z. A Portable Wireless System For Real-Time Electrocardiographic Monitoring. Department of Computer and Information Engineering and Department of Psychology National Cheng Kung University, Taiwan. November 2012.

6. Meda Said Kheerthana and Manjunath A.E. A Survey on Wearable ECG Monitoring System using Wireless Transmission of Data. International Journalof Advanced Research in Computer and Communication Engineering, Vol. 4, Issue 7, July 2015

7. Prakash Vidwan, Pradip Panchal, Sachin Sharma. Real Time Portable Wireless ECG Monitoring System. Asian Journal of Computer Science and Information Technology 2:6 (2012) $158-161$.

8. Tjia, M.O. 1994. Gelombang. Bandung : Institut Teknologi Bandung 
9. 1985. 302 Cicuits By Elektuur B.V. Beek The Netherlands.

10. DatasheetMAX195. 1997

11. Ackerman, Eugene dan Lynda B.M. Ellis. 1988. Ilmu Biofisika. Surabaya : Airlangga University Press.

12. Simmers, Louise. 1988. Diversified Health Occupations. 2nd edition. Page 157 